\title{
Pharmacology learning in Nepal and the Caribbean
}

\author{
Pathiyil Ravi Shankar \\ Editor, JMCJMS
}

Pharmacology is an important subject in the medical school curriculum. Medical students should develop the ability to sort out pharmacological information and concepts from the overload of information which is presented to them, be able to integrate this information into clinically relevant situations and apply this knowledge in the management of a patient's illness [1].

In Nepal and the Caribbean, pharmacology is taught during the first two years of the undergraduate medical course. Most universities in Nepal follow an integrated curriculum and pharmacology is usually learned as a component of different organ systems. The curriculum also emphasizes early clinical exposure and there may be a clinical context to the pharmacology learning. In the Caribbean, only a few medical schools follow an integrated curriculum and many medical schools do not have clinical facilities. Traditionally students complete their clinical rotations in other locations, though, many schools are aiming to provide a degree of early clinical exposure to their students in the islands.

\section{Core competencies in pharmacology:}

An article published in 1997 had recommended core knowledge, skills and attitudes in clinical pharmacology for medical students [2]. Among the knowledge components were basics of pharmacology, monitoring drug therapy, basic pharmacokinetics, adverse drug reactions, drug interactions, principles of prescribing for different patients, management of the poisoned patient, practical criteria for selecting drugs and drug formularies among others. The skill components were prescribing for various populations, seeking information, use of evidence, writing prescriptions, communication skills and patient adherence to therapy. The core attitudes were the process of optimal therapeutics, taking a balanced approach to therapeutics, and learning for the future. Ten basic competencies for undergraduate pharmacology education were highlighted in a recent article [3]. Among these was familiarity with the national list of essential medicines, an understanding of the process of personal drug selection, understanding and responding to pharmaceutical promotion, ability to use unbiased, objective sources of medicine information, analyze prescribing using simple indicators as a tool for improvement, reporting adverse drug reactions, counseling patients regarding management of their condition and ability to 
carry out common pharmaceutical calculations.

\section{Prescribing skills:}

Prescribing skills are an important competency for the physician and studies have shown deficiencies in prescribing skills among medical undergraduates. A European cross-sectional study conducted among final year medical students showed students had a poor knowledge of drug interactions, contraindications, chose inappropriate therapy for common conditions and made prescribing errors [4]. A study in Nepal found the prescribing skills of first and second year students to be unsatisfactory [5]. Prescribing deficiencies were noted in both the physician and the drug-related components. Confidence in prescription writing was recently studied among interns and house officers in Trinidad and Tobago [6]. Medical interns had greater confidence in their ability and were of the opinion that undergraduate training equipped them to write prescriptions safely and rationally. However, this ability was not measured objectively.

\section{Teaching-learning of pharmacology:}

In both offshore Caribbean medical schools and in Nepal, pharmacology is taught explicitly during the first two years of the undergraduate medical course. The topic of therapeutics is addressed during the different clinical rotations but formal training in clinical pharmacology and therapeutics (CPT) is not provided. Recognizing the importance of CPT for rational prescribing and for reducing medication errors, many developed nations have introduced CPT learning throughout the undergraduate medical curriculum $[7,8]$.
The World Health Organization (WHO) and many non-governmental organizations have recognized the importance of strengthening pharmacology education, especially in developing nations. The impact of a short course in pharmacotherapy using the WHO manual 'Guide to good prescribing' was studied in a number of countries, including Nepal [9]. Students from the test group performed better than those in the control group with regard to all presented patient problems.

\section{Learning rational prescribing:}

The process of personal drug selection is an important exercise to teach students to use medicines rationally [10]. An article published in 2013 mentioned that the exercise of personal drug selection was carried out in three medical schools in Nepal [11]. There may be other schools which conduct a few sessions in personal drug selection. Having been an external examiner in pharmacology in Nepal for a few years I can personally attest to the wide difference in practical training in pharmacology in different institutions. My colleagues, who are external examiners in pharmacology, at present, tell me that this is still true.

At a medical school in Nepal P-drug selection, spotter exercises, communicating with a simulated patient, analysis of drug advertisements/promotional material, and analyzing rationality of prescriptions were among the practical exercises conducted and assessed [12]. Some of these exercises are conducted in different Nepalese medical schools. There is a lack of recent scientific literature about the learning exercises and assessment methods in pharmacology which can be an area for future study. 


\section{Pharmacology in offshore Caribbean medical schools:}

In offshore Caribbean medical schools the focus has been on preparing students for the United States Medical Licensing Exam (USMLE) and didactic lectures were the main teaching modality. Things are however, changing with the increasing requirement for accreditation of courses. Offshore schools in general still have the drawback of reduced emphasis on faculty development and unfamiliarity with new methods of teachinglearning. Sessions on faculty development are regularly conducted in some schools and by bodies like the Caribbean Accreditation Authority for education in Medicine and other Health Professions (CAAM-HP). At the Xavier University School of Medicine, Aruba sessions on personal drug selection, patient counseling and analysis of drug advertisements were regularly conducted. Many pharmacology educators in the Caribbean unfortunately may not have the knowledge or the expertise to conduct these sessions. So a regional workshop on newer methods of pharmacology learning and the expected competencies of pharmacology education for medical undergraduates is required.

\section{Pharmacology learning during the clinical years:}

Teaching-learning of CPT during the clinical years poses many challenges. Most pharmacology departments in Nepal struggle to conduct sessions for different groups of health science students during the first two years. Also postgraduate training in Pharmacology does not emphasize clinical pharmacology and pharmacologists are not involved in ward rounds and patient centered activities in most institutions. Hence pharmacologists may not have sufficient knowledge and skills in clinical pharmacology. Also not all institutions have a well functioning pharmacovigilance and drug/medicine information centers and postgraduates may be inadequately trained in these activities. Hence pharmacologists may lack the time, resources and training to contribute to clinical pharmacology teaching during the clinical years. Also many institutions hire pharmacists and $\mathrm{PhDs}$ for pharmacology teaching. These individuals again may not have adequate exposure to and knowledge about clinical pharmacology due to lacunae in their training.

In offshore Caribbean medical schools, teaching hospitals and drug information and pharmacovigilance centers are not present. As mentioned previously the traditional focus has been on preparing students for licensing exams and the dominant teaching modality used is didactic lectures. Clinical rotations are conducted in hospitals in other countries and pharmacologists are not fully aware of the medicine use situation in these countries. Hence incorporating a certain amount of clinical pharmacology education during the clinical years is more challenging. Pharmacology learning during the basic science years is mainly focused on basic pharmacology and addressing important concepts. Addressing rational use of medicines (RUM) during the clinical years can make the learning more focused and clinically relevant. Studying medicine use in 'real' patients will evoke greater student interest and participation.

\section{New medicines:}

Another major challenge is the rapid proliferation of new medicines and biological agents. Cost constraints may limit their use in developing countries. Many of these 
medicines act by modulating the immune system. Understanding these medicines and staying up-to-date with recent advances is increasingly challenging for pharmacologists. Pharmacologists like other doctors should develop adequate self-directed learning skills and should have access to objective, independent sources of medicine information. Institutions in Nepal have full access to the HINARI program of the WHO which can address important information needs. In the Caribbean, a few low to middle income countries have subsidized access to HINARI.

In this editorial, the author has provided an overview of important challenges in pharmacology education for medical undergraduates in Nepal and the Caribbean. Ensuring that all institutions follow university recommendations is a challenge in Nepal while creating a core syllabus which will provide an adequate grounding in RUM is the challenge among offshore Caribbean medical schools.

\section{REFERENCES}

1. Kwan CY. Problem-based learning and teaching of medical pharmacology. NaunynSchmiedeberg's Arch Pharmacol 2002; 366:10-17.

2. Walley T, Webb DJ. Core content of a course in clinical pharmacology. Br J Clin Pharmacol 1997;44:171-174.

3. Shankar PR. Ten basic competencies for undergraduate pharmacology education at KIST Medical College, Lalitpur, Nepal. Australas Med J. 2011; 4(12): 677-682.

4. Brinkman DJ, Tichelaar J, Schutte $\mathrm{T}$ et al. Essential competencies in prescribing: A first European cross-sectional study among 895 final-year medical students. Clin Pharmacol Ther. 2017;101: 281-289.

5. Chapagain K, Paranjape BD, Lama G. Prescribing Skills of First and Second Year MBBS Students of A Teaching Hospital. JNMA J Nepal Med Assoc. 2016; 55(204):72-75.
6. Ignacio D, Sealy P, Clement Y. Confidence in prescription writing among junior physicians in Trinidad and Tobago. West Indian Med J. 2015; 64: 407-412.

7. Richir MC, Tichelaar J, Geijteman EC, de Vries TP. Teaching clinical pharmacology and thera peutics with an emphasis on the therapeutic reasoning of undergraduate medical students. Eur J Clin Pharmacol. 2008; 64: 217-224.

8. Tofovic SP, Branch RA, Jackson EK, Cressman MD, Kost CK Jr. Teaching clinical pharmacology and therapeuti cs: selective for fourth-year medical students. J Clin Pharmacol. 1998;38:670-9.

9. De Vries TP, Henning RH, Hogerzeil HV et al. Impact of

a short course in pharmacotherapy for underg raduate medical students:

an international randomised controlled study. Lancet. 1995; 346: 1454-1457.

10. Shankar PR. Seven semesters of personal drug selection in a Caribbean medical school. Education in Medicine Journal 2015;7:e80e82.

11. Banerjee I. Concepts of P-drug selection. Nepal J Epidemiol 2013;3:226-229.

12. Shankar PR, Gurung SB, Jha N, Bajracharya O, Ansari SR, Thapa HS. Practical Assessment in Pharmacology At A New Nepalese Medical School. J Clin Diagn Res 2010; 4: 3314-3316.

Correspondence to:
Prof. Dr. Pathiyil Ravi Shankar
Associate Dean
Curriculum and Quality Assurance
American International Medical University
Beausejour Road
Gros Islet, Saint Lucia
E-mail: ravi.dr.shankar@gmail.com

Correspondence to: Associate Dean Curriculum and Quality Assurance American International Medical University Beausejour Road E-mail: ravi.dr.shankar@gmail.com 